\title{
District magnitude, electoral formula, and the number of parties
}

\author{
KENNETH BENOIT \\ Department of Political Science, Trinity College, University of Dublin
}

\begin{abstract}
Duverger's propositions concerning the psychological and mechanical consequences of electoral rules have previously been examined mainly through the lens of district magnitude, comparing the properties of single-member district plurality elections with those of multimember proportional representation elections. The empirical consequences of multimember plurality (MMP) rules, on the other hand, have received scant attention. Theory suggests that the effect of district magnitude on the number and concentration of parties will differ with regard to whether the allocation rules are plurality-based or proportional. I test this theory by drawing on a uniquely large-sample dataset where district magnitude and electoral formula vary but the basic universe of political parties is held constant, applying regression analysis to data from several thousand Hungarian local bodies elected in 1994 consisting of municipal councils, county councils, and mayors. The results indicate that omitting the variable of electoral formula has the potential to cause significant bias in estimates of Duvergerian consequences of district magnitude. In addition, the analysis of multi-member plurality elections from the local election dataset reveals counter-intuitively that candidate and party entry may increase with district magnitude under MMP, suggesting important directions for future investigation of MMP rules.
\end{abstract}

\section{Introduction}

No problem in the research on electoral systems has occupied so much attention as the question of how different electoral rules shape a nation's political party system. Recent developments in this research agenda focus on the number of parties active in a country's legislature (Amorim-Neto \& Cox 1997; Taagepera \& Shugart 1993; Ordeshook \& Shvetsova 1994; Riker 1976; Wildgen 1972), in fact a classic question in the literature of political science. Maurice Duverger (1951) provided the most explicit formulation of this proposition; his assertion that 'the simple-majority single-ballot system favors the two-party system' (Duverger 1951: 217) is widely acknowledged as one of the most durable and reliable hypotheses in political science. By providing structural constraints and their concomitant incentives, according to this view, the number of seats to be awarded in a district directly shapes the constellation of the political parties that can win, and hence that will attempt to compete for seats in the legislature. 
In determining the principal features of electoral systems which shape party systems, the concept of district magnitude - the number of seats allocated in an electoral district - is central (Ordeshook \& Shvetsova 1994; Taagepera \& Shugart 1993; Blais \& Carty 1991; Palfrey 1989; Rae 1967). What determines the number of parties active in a nation's national assembly? 'History, present issues, and institutions all intervene. But if one had to give a single major factor [that] determines the number of parties ... it would have to be the district magnitude', according to Taagepera \& Shugart (1993: 455). District magnitude is not the only determinant of the number of parties, of course, but it is considered by many to be 'the decisive factor' (Taagepera $\&$ Shugart 1989: 112; see also Cox 1997; Lijphart 1994; Gallagher 1991: 50; Rae 1967).

In addition to district magnitude, there is another basic mechanism through which electoral systems influence political parties: the type of electoral formula. A fundamental distinction exists between proportional rules that allocate seat shares more or less according to vote shares, and plurality rules that reward the parties or candidates with the largest vote shares with all of the seats. Proportional representation includes all methods using mathematical methods for dividing multiple seats among multiple parties such that their seat shares are more or less commensurate with their votes shares. Plurality rules, on the other hand, tally votes for each party separately and award one or more seats to the top vote winners. Plurality methods differ in kind from PR-based rules in that they allocate seats to the party or parties with the most votes rather than assigning seats according to vote shares. This fundamental distinction motivated Duverger's propositions (1951) and has formed the basis for much subsequent research (Blais \& Carty 1987, 1991; Rae 1967).

Both district magnitude and the electoral formula, therefore, deserve consideration in studying how electoral systems influence the number of parties. This distinction is all the more important when considering the fundamental distinction between proportional- and plurality-based electoral rules. The inkind difference between rule types, it has been suggested, can completely change the direction of the influence of district size on the number of parties. While for proportional type formulas it will be true that larger district sizes will yield more parties, this effect should be reversed when plurality rules decide the winners (Blais \& Carty 1987). 'The relationship between district magnitude and proportionality is reversed under plurality, compared with PR. High $M$ and PR lead to relative proportionality, while high $M$ and plurality lead to extreme disproportionality' (Taagepera \& Shugart 1989). ${ }^{1}$ This suggests that the effects of district magnitude will interact with the effects of electoral formula, and that ignoring these interactive effects will produce biased estimates of the consequences of district magnitude on the number 
of parties. Yet most previous empirical research on the determinants of the number of parties does not include electoral formula as a variable. ${ }^{2}$ The proposition concerning the interactive influence of electoral formula and district magnitude, therefore, remains to be tested empirically.

In what follows I estimate the effects of district magnitude on the number of parties while controlling for the electoral formula. The empirical sample comes from a uniquely large and controlled dataset of several thousand Hungarian local elections held in December 1994. The next section describes this dataset and outlines why it is useful for investigating the effects of electoral rules on the number of parties.

\section{Data and methods}

To estimate the relationship between electoral systems and the number of parties I have drawn from an extensive database of elections to local municipal councils, county councils, and mayors held across Hungary on December 11, 1994. Several compelling factors make this dataset suitable for testing propositions about the interaction of formula and district magnitude in shaping the number of parties.

First, the dataset perfectly fulfills a number of important technical desiderata, namely an enormous number of cases using both proportional and plurality rules across a wide range of district magnitudes. In short, there is tremendous variation in all of the key independent variables. Furthermore, all of the relevant quantities of interest are observed at the district level. The dataset therefore conforms to the widespread yet difficult to follow urging that 'electoral studies ought to move toward constituency-level evidence' (Amorim-Neto 1997: 168; see also Cox \& Shugart 1991; Taagepera \& Shugart 1989: 115, 214).

Second, variation in other variables - such as basic social cleavages, general issue dimensions, and cultural factors - are largely controlled because all of the elections took place in the same country on the same day. While it would probably be claiming too much to state that each locality has an identical 'party system', the major parties in each locality are nearly always the same national parties that contest parliamentary elections, thus providing a basic continuity across units. Different localities will have different interests and weight issues differently, yet the basic issue dimensions themselves are relatively constant. This is quite different from cross-national samples where not only the party weights but also the basic issue and cleavage dimensions themselves are likely to differ in significant ways. In this sense the control on party systems offered by local elections is at least as good as, if not much better than, research which draws on cross-national elections. 
Finally, the fact that Hungarian experience with democracy was still recent in 1994 - having held only one set of local elections previously in 1990 makes the test for Duvergerian effects even more stringent. As Reed (1990: 356) suggests, the incentives produced by electoral laws require time to take effect, as parties gain experience in a learning process. 'Players who do not win, who are unable or unwilling to use optimal strategies, tend to exit'. The newness of democratic experience makes the test harder, not easier; observation of Duvergerian effects in Hungarian local elections should therefore be taken as serious evidence that the forces Duverger described do indeed operate.

\section{Local electoral systems in Hungary}

The Hungarian law on local elections ${ }^{3}$ establishes the rules which govern voting on a single day for all local bodies nationwide. There are four different kinds of electoral bodies, each with distinct rules: two types of municipal councils, from either towns and villages of 10,000 residents or less, or cities of more than 10,000 residents; county assemblies, including the Budapest assembly; and mayors in towns, villages, and cities.

\section{Towns and villages}

Municipalities of 10,000 inhabitants or less in Hungary use 'small lists' treating the municipality as a single district whose magnitude is determined according to a population-based scale. ${ }^{4}$ This assignment mechanism has the advantage of guaranteeing variation in district magnitudes while also providing a very good assurance that their values are exogenous to the local configurations of political parties. It also ensures a roughly constant population or population-per-seat for each district. Seats are awarded using a multi-member plurality (MMP) or 'first-past-the-post' rule, defined here as a system which allows each voter to cast $M$ votes - one each for up to $M$ candidates - and the top $M$ vote-winning candidates are declared elected. This format is sometimes used in U.S. local elections, known as the 'at-large' ballot but also called the 'bloc vote' (Carey \& Shugart 1995) or the 'pure atlarge' system (Engstrom \& McDonald 1993). In 1994 there were 2,985 such electoral bodies.

\section{Cities}

Municipalities of more than 10,000 inhabitants use mixed electoral rules to elect their town councils. Each such municipality is divided into singlemember districts (SMDs); each voter casts a single-vote, candidate-based ballot in the SMD where the voter resides. In each SMD, the candidate with the most votes wins the seat. A compensation list for the entire municipality 
forms the other part of the system, drawing on votes cast for parties in the SMD contests that did not go towards winning an SMD mandate. Compensation list seats are awarded to parties from lists of candidates that parties have submitted before the election. A special version of the Sainte-Laguë highest average proportional representation formula ${ }^{5}$ then determines the allocation of seats. As in the towns and villages, the number of seats to be awarded on each list, as well as the total number of SMDs in the city, are legally assigned according to a population-based scale. ${ }^{6}$ There were 162 municipalities classified as cities in 1994, together containing a total of 2,073 single-member districts and 162 compensation lists.

\section{County assemblies}

Hungary is divided into 19 counties, each having a proportionally-elected council, plus the capital Budapest with its 66-member 'Metropolitan Council'. Parties compete for seats from list ballots, awarded using the Hungarian version of the Sainte-Laguë PR method. A legal threshold requirement also states that no party with less than 4 percent of the total votes in the county or municipal election may receive seats. Parties may submit two lists in each county: one for voting in municipalities of up to 10,000 inhabitants and one for voting in municipalities of more than 10,000 inhabitants. Ballots are counted and seats awarded separately according to the classification of municipal size. There are 19 counties plus Budapest, making a total of 39 list elections (since there is no city or town list for the Budapest council) ranging in district magnitude from 5 to 66 .

\section{Mayors}

Mayors are elected in each town, village, and city according to single-member plurality rules (the single candidate with the most votes becomes mayor). In the 1994 sample there were 2,985 mayors elected from small municipalities, 162 from large municipalities, and one from Budapest. ${ }^{7}$

\section{The dataset}

The final dataset of elections and electoral systems contains 8,377 different observations, each consisting of a district election held according to a distinctly identifiable electoral rule, differing primarily with respect to district magnitude and to whether a plurality or a proportional rule governed the allocation of seats. ${ }^{8}$ Table 1 summarizes the dataset according to electoral formula and district magnitude.

Several variables from this dataset will be of interest to this study, all single quantities calculated from elections to a single electoral body. These are: 
Table 1. District magnitude frequencies in 1994 Hungarian local elections

\begin{tabular}{lrrrrrrrrr}
\hline & \multicolumn{8}{c}{ District magnitude } & \\
\cline { 2 - 7 } Formula & 1 & $2-5$ & $6-9$ & $10-15$ & $16-20$ & $21-30$ & $31-40$ & $41-66$ & Total \\
\hline & & & & & & & & & \\
Plurality & 5,199 & 1,136 & 1,495 & 346 & 0 & 0 & 0 & 0 & 8,176 \\
Proportional & 0 & 1 & 126 & 41 & 12 & 12 & 7 & 2 & 201 \\
Total & 5,199 & 1,137 & 1,621 & 387 & 12 & 12 & 7 & 2 & 8,377 \\
\hline
\end{tabular}

M District magnitude, or the number of seats awarded in the district. Since each elected body has only one district magnitude, this number is not an average but rather the actual number of seats awarded in the district election constituting the observation.

PR A dummy variable taking a value of 1 if the election used any form of proportional representation, and 0 if it took place under plurality rules. Plurality rules here are defined as those governing the 3,136 mayoral elections and the 2,977 MMP 'small lists'.

EFFNELEC The 'effective' number of parties contesting the election. This quantity is calculated as $1 / \sum v_{i}^{2}$ for all parties eligible to receive votes, where $v_{i}$ represents party $i$ 's proportion of the vote. Because this measure discounts parties with small vote shares, it measures the voter appeal of parties rather than the simple number of parties.

ACTNELEC The simple or actual number of parties contesting the election.

EFFNPARL The effective number of parties winning seats, calculated as $1 / \sum s_{i}^{2}$ for all parties receiving seats, where $s$ represents the party $i$ 's proportion of the vote. This measure is widely used to provide a more realistic representation of seats in the parliament, since it counts parties with many seats more strongly than parties with relatively few seats.

INDEPRATIO The ratio of independent candidates to total candidates running in the election.

AVGCOALP The number of parties joined in a coalition, averaged over the total candidacies (or number of party lists). For example, in a district where three candidates represented single parties, two candidates were jointly supported by two parties each, and a sixth candidate was backed by a three-party coalition, AVGCOALP would be $(1+1+1+2+2+$ 3) $/ 6=1.67$. 
MAXCANDP The vote proportion of the winning candidate or largest votewinning party.

WINSEATP The seat proportion of the winning candidate or largest votewinning party.

BONUSRAT The bonus ratio of seats to votes awarded to the party winning the largest number of votes, calculated as WINSEATP/MAXCANDP. This measure is identical to the 'advantage ratio' of Taagepera \& Laasko (1980) applied to the largest party.

DISPRLS Gallagher's least-squares disproportionality index, similar to the well-known Loosemore-Hanby index (Loosemore \& Hanby 1971) but registering small discrepancies less than large ones (Gallagher 1991). It is calculated as $\sqrt{\frac{1}{2} \sum_{i}\left(v_{i}-s_{i}\right)^{2}}$, and ranges from 0 to 100 . A zero indicates perfect proportionality, and a 100 means that somehow a candidate with no votes won a seat.

Table 2 presents sample means for each of the main quantities of interest, broken down by type of election. These values provide a simple benchmark for comparisons but are provided primarily in order to understand better the inferential statistics presented in the sections which follow.

\section{Modeling electoral systems consequences}

The effects of district magnitude, according to theory, operate in two ways. Part of this effect will be 'mechanical', where the electoral rules simply impose mathematical constraints on the number of parties that may win parliamentary seats. At its simplest, when $M$ represents district magnitude, a maximum of only $M$ parties may win seats. This effect comes directly from the character of electoral structure which intervenes between parties' shares of the vote and their shares of parliamentary seats. It deals only with the number of parties in parliament, not the number contesting the election. The second effect is 'psychological', operating on both voters and party elites, affecting electoral competition given the anticipation of the mechanical effect. Voters will not wish to waste their support on small parties whom the electoral rules will in all likelihood prevent from winning any seats. Likewise, party leaders who expect not to win seats may be encouraged to form coalitions, withdraw candidacies in certain districts, or even disband their party. The psychological effect therefore affects the distribution of votes, while the mechanical factor affects the distribution of seats. As Blais \& Carty (1991: 80 ) point out, these are two distinctly different mechanisms which I therefore treat consecutively. 
Table 2. Quantities of interest by type of electoral rule

\begin{tabular}{lccllllrr}
\hline \multirow{2}{*}{ Elected body } & EFFNELEC & ACTNELEC & $\begin{array}{l}\text { Prop. } \\
\text { Indeps. }\end{array}$ & AVGCOAL & EFFNPARL & BONUSRAT & DISPRLS & $N$ \\
\hline Mayoral & 1.92 & 2.79 & 0.83 & 1.09 & 1.00 & 1.57 & 26.00 & 3,136 \\
City SMDs & 4.17 & 6.06 & 0.11 & 1.49 & 1.00 & 2.90 & 50.44 & 2,063 \\
City PR & 5.27 & 7.46 & - & 1.35 & 4.37 & 1.13 & 7.97 & 162 \\
Town MMP & 10.87 & 14.36 & 0.93 & 1.02 & 6.36 & 1.17 & 14.02 & 2,977 \\
County PR & 5.44 & 9.49 & - & 1.25 & 4.55 & 1.12 & 5.61 & 39 \\
Total & 5.74 & 7.83 & - & 1.17 & 2.99 & 1.74 & 27.32 & 8,377 \\
\hline
\end{tabular}


I employ a dummy variable $P R$ to distinguish proportional from plurality rules. Estimating a coefficient for this quantity treats the in-kind difference between an allocation rule's interaction with district magnitude as a hypothesis to be tested. In the dataset the elections coded as having values of $P R$ $=0$ are the 3,136 mayoral elections and the 2,977 multi-member plurality elections. For most samples analyzed in the next two sections this dummy variable distinguishes between two election types, for example between the 2,977 town and village MMP elections and the 39 county list PR elections.

The statistical model used here follows the curvilinear function common to previous studies (e.g., Amorim-Neto \& Cox 1997; Ordeshook \& Shvetsove 1994; Taagepera \& Shugart 1993; see Sartori 1986 for a rationale). This model assumes that the marginal effect of district magnitude on the number of parties will diminish as district size increases. To accomplish this I use the (base-10) $\operatorname{logarithm} \log M$ instead of the simple value of district magnitude in all estimations, consistent with previous research (Amorim-Neto \& Cox 1997; Taagepera \& Shugart 1989, 1993).

The general specification is:

$$
Y=b_{0}+b_{1} \cdot \log M+b_{2} \cdot P R \cdot \log M+b_{3} \cdot P R+e,
$$

The first term is a constant; the second term, $b_{1} \cdot \log M$, indicates the log-linear effect of district magnitude. The third and fourth terms indicate the interaction of using PR rules with larger district magnitudes instead of the base case of plurality rules. Using this pair of terms permits both the magnitude and the average values of the relationship to change when changing from plurality to PR rules. When plurality rules are used both the third and fourth terms will be zero, yielding the case of:

$$
Y=b_{0}+b_{1} \log M+e .
$$

When PR rules apply, the relationship will be:

$$
Y=\left(b_{0}+b_{3}\right)+\left(b_{1}+b_{2}\right) \log M+e .
$$

Ordinary least-squares (OLS) estimation is used for all models, primarily to maintain continuity with previous research and because the simplicity of interpreting this model in the current context outweighs the gains from making more sophisticated distributional assumptions. Because of potential heteroskedasticity issues in the data, the standard errors of all regression coefficients have been computed using White's heteroskedasticity consistent method (White 1980). 


\section{Estimating the psychological effect}

The psychological impact of electoral systems can be measured at two levels, according to whether the structural incentives operate on voters who must decide which parties to support or on the political elites deciding to form parties (Blais \& Carty 1991). The first can be measured by the degree of fractionalization of the vote, measured by the effective number of parties in the electorate (EFFNELEC). In proportional systems of high district magnitude where even small parties stand a good chance of winning seats, the effective number of parties in the electorate should be higher than in elections held under more restrictive systems, where voters supporting smaller parties 'stop doing so because they feel it would be a waste of their vote' (Taagepera \& Shugart 1989: 65). Furthermore, when seats are distributed according to plurality rules, we should expect the vote to be 'more polarized... as voters refrain from wasting their votes on minor parties' (Blais \& Carty 1991).

\section{The consequences of controlling for electoral formula}

The basic psychological effect of electoral rules on the number of parties is estimated in Table 3. Models (1) and (2) with the effective number of parties EFFNELEC as a dependent variable represent the psychological effect of electoral rules on voters; models (3) and (4) with the actual number of parties ACTNELEC represent the psychological effect on parties and party elites. Each dependent variable is regressed twice on logged district magnitude, once with the dummy variable indicating PR and once without. All four of the regressions use all of the multi-member elections as their sample, drawn from the town MMP and county PR lists. ${ }^{9}$

An immediate result of Table 3 is the bias shown in the estimates of the consequences of district magnitude when omitting the interactive variable for type of electoral rule. Specifically, models (1) and (3) overestimate the consequences of district magnitude for PR systems, and underestimate the relationship from the data for the plurality elections. The coefficient estimate for $M$ of 13.51 in regression (1), for example, gives a completely biased picture of the effects of district magnitude. Only when the interactive term is added in regression (2) does it become clear that plurality and PR elections exhibit distinctly different responses to the effects of district magnitude. Measurements of the effects of district magnitude that fail to distinguish between PR and plurality rules may therefore lead to unreliable and biased results because they are literally mixing two quite different phenomena.

The in-kind differences in the sample between the effects of district magnitude in plurality and PR elections are graphically portrayed in Figure 1. Here the MMP sample ranges from 3 to 13 in district magnitude, and the 
Table 3. Estimating the psychological effect

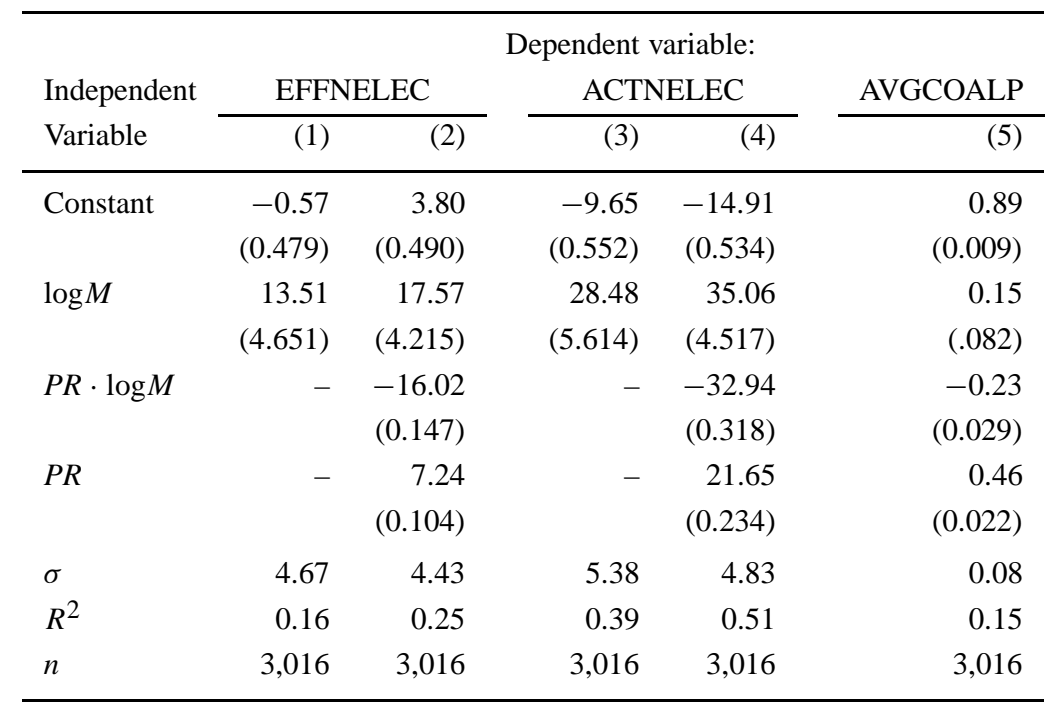

Note: Heteroskedasticity-corrected standard errors are in parentheses; $\sigma$ is the standard error of the estimate. The sample include 39 county council PR elections and the 2,977 MMP town and village elections.

number of parties increases significantly as $M$ increases, both for the effective and actual numbers of parties. The number of parties in the PR sample, on the other hand, also increases as $\log M$ increases, but at a much smaller rate than in the MMP elections. The coefficient for $\log M$ combining the dummy variable estimate in result (2) is 1.55 (computed as 17.57-16.02). This value indicates, for example, that under PR rules, when $m=10$ we would expect 1.6 effective parties, 2.0 effective parties at $m=20$, and 2.30 effective parties at $m=30$.

A secondary analysis of the psychological effect using alternative measures also reveals evidence of a psychological effect tending to concentrate parties as district magnitude increases. The final column of Table 3 (column 5 ) estimates the average number of electoral coalition partners ${ }^{10}$ as a function of $\log M$, finding a significant positive relationship between coalitions and $M$ in MMP elections, and a significant negative relationship between coalitions and $M$ in PR systems. Anticipating the advantages of greater size, parties tend to coalesce more in PR districts with smaller magnitudes. Contrariwise, as parties see the greater potential for exclusion by coordinated large parties as district magnitude rises under MMP, they also tend to coalesce. Both results are consistent with the prior theoretical expectations concerning the psychological effect of district magnitude. 


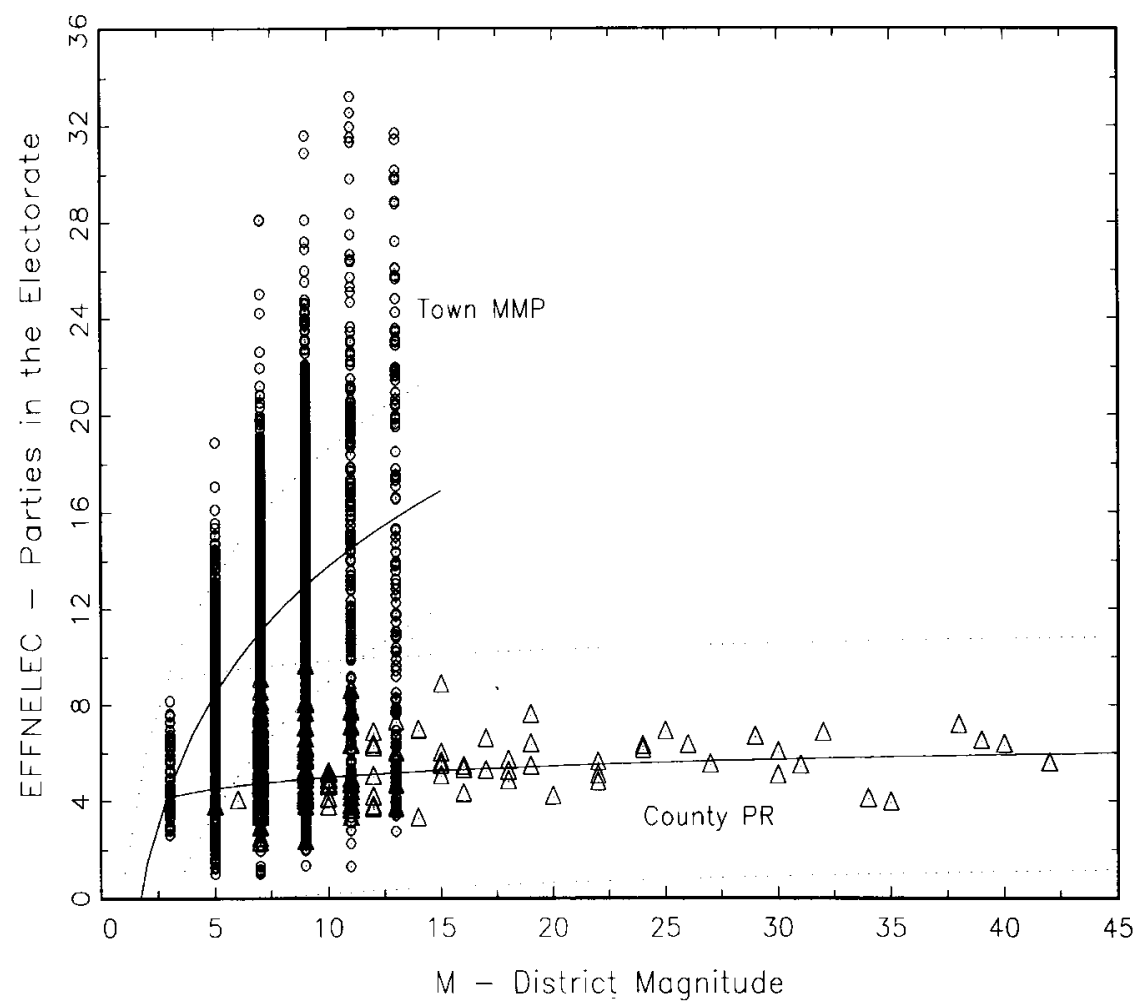

Figure 1. The psychological effect: effective number of competing parties by $M$ (Table 3, Regression 2).

On the whole results of controlling for electoral formula confirm that the number of parties responds differently to increases in district magnitude depending on whether PR or plurality rules are used. Unexpectedly, however, the number of parties increases with district magnitude at a far higher rate under plurality rules than under PR - contrary to theoretical expectations suggesting the opposite. This result apparently contradicts the finding of Blais \& Carty (1991: 89) that 'the psychological factor seems unambiguous in plurality systems, working exactly as predicted by Duverger'. How can this counterintuitive finding be explained?

The curious case of independent candidacies under MMP

More so than in any other electoral jurisdiction, for the MMP-elected municipal councils many candidates chose to compete as independents rather than being officially linked to a party. In these elections the proportion of independents was 0.93, compared to just 0.11, for example, in the SMD 
DISTRICT MAGNITUDE, ELECTORAL FORMULA, AND THE NUMBER OF PARTIES 215

Table 4. Examining the puzzle of independent candidates

\begin{tabular}{|c|c|c|c|c|}
\hline \multirow{4}{*}{$\begin{array}{l}\text { Indep. } \\
\text { Variable }\end{array}$} & \multicolumn{3}{|c|}{ Dependent. Variable: EFFNELEC } & \multirow{4}{*}{$\begin{array}{r}\text { INDEPRATIO } \\
\text { MMP } \\
\text { Only } \\
(9)\end{array}$} \\
\hline & No & No more than 5 & No more than 10 & \\
\hline & Independents & Independent Cands. & Independent Cands. & \\
\hline & (6) & (7) & (8) & \\
\hline \multirow[t]{2}{*}{ Constant } & -1.38 & -4.05 & 5.99 & -0.20 \\
\hline & $(0.306)$ & $(0.396)$ & $(0.361)$ & $(0.011)$ \\
\hline \multirow[t]{2}{*}{$\log M$} & 3.87 & 0.90 & 0.99 & 0.33 \\
\hline & $(1.024)$ & $(1.180)$ & $(1.585)$ & $(0.090)$ \\
\hline \multirow[t]{2}{*}{$P R \cdot \log M$} & -2.32 & 0.64 & 0.55 & - \\
\hline & $(0.273)$ & $(0.421)$ & $(0.232)$ & \\
\hline \multirow[t]{2}{*}{$P R$} & 4.81 & -0.61 & -2.55 & - \\
\hline & $(0.194)$ & $(0.299)$ & $(0.165)$ & \\
\hline \multirow[t]{2}{*}{$\log$ population } & - & - & - & - \\
\hline & & $(1.301)$ & $(1.745)$ & \\
\hline$\sigma$ & 0.98 & 1.44 & 1.98 & 0.10 \\
\hline$R^{2}$ & 0.38 & 0.04 & 0.02 & 0.17 \\
\hline$n$ & 869 & 366 & 1,201 & 2,977 \\
\hline
\end{tabular}

Note: Heteroskedasticity-corrected standard errors are in parentheses; $\sigma$ is the standard error of the estimate. PR elections are the 39 county council elections in contrast to the 2,977 MMP town and village elections. 'No Independents' column (6) means that all measures were recomputed ignoring independent candidacies.

elections held in the larger municipalities (see Table 2). The phenomenon of independent candidacies therefore deserves more systematic investigation to determine whether it is a unique phenomenon or rather something linked systematically to incentives created by electoral system effects.

Table 4 presents additional results designed to unravel the puzzling phenomenon of independent candidacies. Models (6) and (7) re-estimate the effects of district magnitude and electoral formula on the number of parties while limiting or eliminating independent candidates. Model (6), for example, uses a sample ignoring all independent candidates to see if parties also proliferated in response to increasing district magnitude under MMP. The strongly significant coefficient of 3.87 on $\log M$ indicates that they did indeed, lending support to the general finding that counter to expectations, increasing district magnitude may be linked to increased fragmentation under MMP.

Models (7) and (8) rely on the original sample containing independents, yet disregard districts containing more than a fixed number of independents. The results here also show a positive and statistically significant increase between district size and the number of parties under MMP, although the 
effect is dampened by eliminating the extreme districts containing nearly all independents. Consistent across models (6) to (8), the estimated effect of $\log M$ on the number parties for PR systems is 1.54 to 1.55 (adding the plain and dummy coefficients on $\log M$ ), exactly consistent with model (2).

We might also investigate directly whether the number of candidates and parties is systematically linked to district magnitude. Model (9) examines the relationship between district magnitude and the proportion of independent candidates (INDEPRATIO, calculated as the total number of independents divided by ACTNELEC). The results shows an extremely strong positive and statistically significant relationship between independent candidacies and district size. In other words, the more seats available, the more independent candidacies arise. This undeniable empirical result is quite unexpected from the standpoint of prior electoral systems theory, which suggests that the potential for increasing disproportionality as $M$ increases under MMP would lead to a concentration and reduction of candidacies and parties. As proven by the results presented here, however, this mechanism may work quite differently in practice. Note that this does not in any way contravene the main object of this study - to demonstrate the importance of controlling for the interactive effects of district magnitude with electoral formula - but it does uncover an intriguing and unexpected result concerning the nature of these effects. The remainder of this subsection looks more deeply at the phenomenon of MMP as district magnitude increases.

The proliferation of parties and candidacies under MMP appears to be linked to the nature of personalistic ties in the towns and villages, combined with the pressures for personal rather than partisan appeals offered by the unusual MMP rules. Most of the municipalities using MMP are small villages of less than 3,000 inhabitants where personalities are well-known and a strong party identification or organization may be lacking. Because of the increased personal contact and the fact that nearly all candidates are likely to be known personally in the towns and villages which use the MMP rules, candidates may be more likely to emphasize their personal appeal rather than their party affiliations. This is precisely the consequence predicted by Carey \& Shugart (1995: 430) who speculated that 'rather than decreasing, the importance of personal reputation actually increases with magnitude in those systems in which copartisans compete with each other for votes and seats'. Indeed, anecdotal evidence suggests that in Hungary many parties chose to run their candidates in towns and villages as independents rather than as party candidates for political reasons. This incentive in turn eliminates the party coordination of candidate entry seen at the county and national levels in Hungarian elections, leading to a proliferation of individuals all seeking independently to win one of the multiple seats available. It is impossible to tell 
from the data, however, which of the thousands of 'independent' candidates were genuinely independent and which were in fact known to be affiliated with a political party. ${ }^{11}$

A more abstract explanation concerns the rationality of entry in MMP. First, each party seeking to capture all of the MMP seats has an incentive to run $M$ candidates, this being the smallest number of candidates which permits a bloc win of all $M$ seats while not having to share the party's votes with an $(M+1)$ th candidate. Yet this does not explain why tiny parties or independents would enter the race, since these would be unlikely to win any seats. Yet the rationality of entry for single candidates is linked to the total number of candidacies, which limits the vote proportions a candidate needs to win a seat. As $M$ increases under MMP, the threshold of exclusion increases while the threshold of inclusion decreases (see Rae et al. 1971). In other words, while the proportion of votes which a candidate must gain in order to guarantee her a seat under MMP $(M /(M+1))$ rises as a function of district size, the minimum proportion of votes with it is possible to win a seat $(M / n)$ gets smaller as the total number of candidates $(n)$ increases, since each voter can cast up to $M$ votes on her ballot. This implies that the number of candidacies will depend both on how many seats are available to win, as well as each prospective candidate's calculation of how many other competitors will decide to enter. The consequence is that the decision for entry is a combination of rule incentives and a signaling game with other candidates. When personalistic appeals dominate party appeals and the discipline for party bloc voting is absent, more candidates may enter the race as the threshold of inclusion is seen to decrease.

Together this logic suggests an interesting and heretofore unexplored dynamic of strategic coordination under MMP, pointing to interesting avenues for future research. The empirical results presented here are consistent with such a hypothesis, and underscore the potential difference between theory and practice in MMP's shaping of the number of parties. Voters seem to support more parties and political elites enter more candidacies as district magnitude increases. The strong finding that in the MMP elections the proportion of independent candidacies is a systematic function of increasing district magnitude cannot be ruled out as a mere 'exception' to the psychological effect. Instead it needs to be investigated further to see if the mechanism described by Carey \& Shugart (1995) is indeed operating, which would indicate a definite psychological effect, albeit rather different than the type generally expected under plurality rules. 


\section{Estimating the mechanical effect}

The mechanical effect of electoral systems refers to the character of the transformation by the electoral rules of votes into seats. The more seats that exist, the more shares there are to be distributed. When these shares are allocated proportionally, the effect should be both greater proportionality as well as a higher number of effective parties in the parliament. District magnitude 'affects the proportionality of PR more than do the various mathematical translation formulas...the smaller the district the lesser the proportionality and, conversely, the larger the district the greater the proportionality' (Sartori 1986: 53). Of course, as previously stated, the expectation is that this relationship will be reversed when plurality rules are exployed, justifying the use of the $P R$ dummy variable in estimating the mechanical effect as well.

Table 5 presents estimates for the mechanical effect of district magnitude on three quantities. The first (model 10), using the effective number of parliamentary parties (EFFNPARL) as the dependent variable, produces statistically significant coefficients on $\log M$ of 9.9 for the MMP elections and 1.4 for the PR elections. This is confirmation that higher district magnitudes are associated with greater numbers of parties in parliament. Once again, however, the unexpected result is found that this effect is markedly stronger for the MMP elections.

How should these results be interpreted? First, it should be recognized that the (unlogged) slope of the relationship between district magnitude and the number of parties elected is constrained between zero and one. ${ }^{12}$ The estimates in column (10) of Table 5 fall within this boundary, as do those from previous research. Previous estimates from nationally aggregated election data of the coefficient on $\log M$ range from 0.34 (Ordeshook \& Shvetsova 1994: 111) to approximately 2.30 (Taagepera \& Shugart 1993). The estimate of 1.4 in the Hungarian dataset is quite precise and its differences from previous estimates may have to do with the fact that it is district data rather than aggregated (as have been all previous studies of this issue), and possibly due to the fact that a single PR formula governs all elections (rather than different formulas having been average together, as previous research has also done). In comparative terms, the Hungarian Sainte-Laguë formula has been shown to be ranked in the upper middle of PR formulas in terms of disproportionality (Benoit 2000).

Another explanation of the result points to the high number of independent candidacies. In fact, the results illustrate one of the principal problems of estimating the mechanical effect when there is also a psychological effect has also been demonstrated. Because the mechanical effect's allocation of seats depends on a given distribution of votes, and because the distribution of votes (and candidacies) is shaped by the psychological effect, estimates of 
DISTRICT MAGNITUDE, ELECTORAL FORMULA, AND THE NUMBER OF PARTIES 219

Table 5. Estimates of the mechanical effect of district magnitude

\begin{tabular}{lrrr}
\hline & $\begin{array}{r}\text { Dep. Var: } \\
\text { EFFNPARL }\end{array}$ & $\begin{array}{r}\text { Dep. Var: } \\
\text { BONUSRAT }\end{array}$ & $\begin{array}{r}\text { Dep. Var: } \\
\text { DISPRLS }\end{array}$ \\
Indep. & MMDs Only & All & MMDs Only \\
Variable & $(10)$ & $(11)$ & $(12)$ \\
\hline Constant & -1.92 & 1.56 & 18.03 \\
& $(0.184)$ & $(0.010)$ & $(0.411)$ \\
$\log M$ & 9.91 & -0.46 & -4.81 \\
& $(1.651)$ & $(0.164)$ & $(2.950)$ \\
$P R \cdot \log M$ & -8.51 & -1.25 & -3.70 \\
& $(0.284)$ & $(0.070)$ & $(0.591)$ \\
$P R$ & 4.93 & 1.33 & -2.04 \\
& $(0.279)$ & $(0.390)$ & $(0.631)$ \\
$\sigma$ & 1.66 & 0.61 & 3.72 \\
$R^{2}$ & 0.43 & 0.55 & 0.19 \\
$n$ & 3,178 & 8,377 & 3,178 \\
& & & \\
\hline
\end{tabular}

Note: Heteroskedasticity-corrected standard errors are in parentheses; $\sigma$ is the standard error of the estimate. 'MMDs Only' indicates that only the districts with $m>1$ were included in the sample, including the 162 compensation lists in small municipalities.

the mechanical effect taken through cross-election samples are fundamentally flawed. The results presented in column (10) of Table 5 support this interpretation. The stronger link between the number of elected parties and $M$ using plurality rules is driven by the psychological effect discussed earlier causing a proliferation of independent candidacies Likewise, the mild positive relationship of the psychological effect also drives the mildly positive estimates for the PR subsample. The comparison underscores the problem with measuring the mechanical effect in this fashion: the fragmentation of parties elected depends heavily on the fragmentation of the parties competing for seats. Interpreting the 'mechanical effect' by estimating the relationship between $M$ and the number of elected parties will therefore always produce coefficients which are generally correct, but always precisely meaningless in terms of their comparability to similar estimates from different data.

Models (11) and (12) of Table 5 attempt to provide estimates that avoid this endogenous cycle. Model (11) is the regression of the bonus given to the largest party on $\log M$. It indicates that while the ratio of seats won to votes 
won for the largest party declines under MMP with increasing $M$, it declines at a steeper rate for PR. This sample includes the SMD races from the mixed city elections (considered in this context as a special case of PR with $M=1$ ), which means that at $M=1$ for PR the largest party's seat proportion is 2.89 times its share of the vote. When $M=10$, on the other hand, this bonus will be only 1.18 , and at $M=20,0.67$.

Model (12) considers the discrepancy between votes and seats for all parties, summarized in the least-squares disproportionality index. The estimated coefficients are well in accord with theoretical expectations: the global disproportionality of the result declines sharply as a function of increasing district magnitude under PR. For MMP, however, disproportionality also decreases with increasing district magnitude - once again directly opposite to prior theoretical expectations. Nonetheless, this MMP effect $(-3.70)$ is not as pronounced as the effect for PR rules (combined coefficient of -8.51).

The fact that parties and candidates proliferate as $M$ increases in MMP rules may give good cause to reconsider our expectations about the number of parties, but it appears that the conventional wisdom concerning the interaction of district magnitude and the proportionality of the result are correct. These results nonetheless underscore the fact that the mechanical effect operates for a given set of votes, and these votes are shaped by the psychological effect. This suggests that future attempts to measure the mechanical effect through empirical observation should use some form of structural model which controls for the endogeneity of the mechanical effect to the psychological forces through which electoral laws pre-filter the number of parties and the votes which they receive.

\section{Conclusions}

The conclusions from the empirical measures of the effects of district magnitude and electoral formula on the number of parties in the Hungarian local elections are as follows:

1. Under PR, the number of effective and actual parties was confirmed to increase positively and significantly as a function of district magnitude in a manner consistent with previous research.

2. When electoral formula was not controlled for, both the estimates of the psychological and mechanical effects of district magnitude were biased. The effects of increasing district magnitude under PR is empirically confirmed to be different in-kind from the effects of increasing district magnitude under plurality rules.

3. As district magnitude increased under PR, the average size of electoral coalitions decreased as fewer parties felt the advantage of grouping in 
order to win seats. As district magnitude increased under MMP, however, the average coalition size of parties increased, consistent with general theoretical expectations about the increasing disproportionality under this formula type.

4. The bonus ratio awarded to the largest party decreases in both PR and MMP districts, although at a much faster rate under PR.

5. Contrary to prior theoretical expectations, under MMP rules the number of parties and the number of candidates rose significantly as district magnitude increased. This was demonstrated to be true for for independent candidates, in samples of districts with limited numbers of independent candidates, and in samples recalculated without independents.

6. Disproportionality decreases in PR as district magnitude increases. While decreasing at a slower rate than under PR, disproportionality also decreased as districts got larger under MMP - again contrary to theoretical expectations.

While the findings about MMP are unexpected and deserve greater study, this analysis points unequivocally to the conclusion that the electoral formula must be controlled for when considering the consequences of district magnitude. Quite simply, PR and plurality rules interact with district magnitude in a manner different in kind on the number of parties. Future research on the number of parties should therefore carefully and explicitly consider the different interactive effects of formula and district magnitude before drawing conclusions.

This study also demonstrates some of the challenges in searching for institutional determinants of the number of parties, and develops and applies some alternative measures for this purpose such as the bonus ratio and the average number of electoral coalitions. In addition, the introduction of the publicly available Hungarian local election dataset provides researchers with new empirical material for extending the study of electoral research. The advantages from this dataset - control of other variables and large-sample size - suggest that extension to the local elections of other countries offers a promising avenue for future research.

The most interesting new result to emerge from the examination of Hungarian local elections is the pattern of proliferating candidacies in the towns and villages using MMP. Previous investigations of multi-member plurality rules have primarily taken place in the context of the debate on the minority representation in the United States (e.g., Engstrom \& McDonald 1993). These results need to be renewed and extended in the context of different party systems. The results from the MMP districts in Hungarian towns and villages should be applied with circumspection to the theoretical expectations concerning the effects of plurality and district size, since the Hungarian 
party system at the local level was still developing and because political actors at this level were still learning how electoral structures affected the consequences associated with their actions. The results nonetheless illustrate what is possible under MMP rules, offering both puzzles for future formal work as well as the empirical data to begin testing them.

\section{Acknowledgments}

Thanks to Gary Cox, Michael Marsh, and Gábor Tóka for comments and to Péter Kovács at the OSZH, Budapest for his invaluable assistance in compiling these local election data. The full data set and code used in this paper are available upon request or for download at http://benoit.tcd.ie/papers.html.

\section{Notes}

1. This includes the extreme case of 'winner-take-all' systems where the plurality party automatically wins all of the seats in the district, but even for standard MMP systems such as those used previously in Turkey and Norway, 'the outcome is likely to be highly disproportional' (Taagepera \& Shugart 1989: 23). I thank Matthew Shugart for clarifying the original intent of this passage.

2. For instance, Amorim-Neto \& Cox (1997), Ordeshook \& Shvetsova (1994), and Taagepera \& Shugart (1993) group both plurality-based systems such as the United States, Great Britain, and Japan, as well as a myriad of PR and mixed systems using different specific PR formulas. None of these studies, however, attempts to control for the in-kind differences between PR and and plurality systems. While these studies did not include plurality systems where district sizes exceeded one - with the debatable exception of Japan's single non-transferable vote system - this omission itself is a subject of this paper.

3. Act LXII of 1994 on the Election of Members of Municipal Governments and Mayors.

4. The election law assigns district magnitude based on population as follows: $0-100, m=$ 3 ; 101-600, $m=5 ; 601-1,300, m=7 ; 1,301-2,999, m=9 ; 3,001-4,999, m=11$; $5,001-10,000, m=13$.

5. The 'Hungarian' Sainte-Laguë uses the series $1.5,3,5,7, \ldots$, slightly different from the traditional Sainte-Laguë starting with a 1, or the 'modified' Sainte-Laguë series of $1.4,3,5,7, \ldots$. See Gallagher (1991).

6. The schedule is as follows: 10,001-25,000 residents, 10 SMDs and 7 list seats; 25,001$50,000,14$ and 9; 50,001-60,000, 15 and 10;60,001-70,000, 16 and 11; thereafter one additional SMD for each additional 10,000 residents and one additional list seat for each additional 15,000 residents.

7. The dataset contains information on only 3,136 mayoral elections (out of 3,147) because not all of the mayoral races were valid.

8. The dataset also includes simulated elections 2,211 PR elections whose results were simulated using actual votes but 10 additional types of proportional elections rules; however, these simulated elections are excluded from the data analyzed in this paper. This full 
replication dataset includes a codebook, the constituent datasets of Hungarian electoral and geographical data, and the Gauss code used to create the final dataset.

9. The $M=1$ elections are excluded because the logarithmic specification for $M$ precludes the existence of effects at $M=1$, since $\log (1)=0$, and because technically all PR rules become equivalent to plurality at $M=1$. The city PR elections are likewise not included because they are a compensation mechanism for which no ballots are directly cast.

10. Electoral coalitions in this context refer to parties registering together to sponsor candidates in a district.

11. The rules for counting parties in the dataset, except for the recalculated version in model (5), count as separate parties both single-candidate parties and candidates declared as independents. Another explanation I considered was that the number of parties and candidacies increased as a function of population, indicating that the needs for representation depended on the social complexity of demands rather than institutional incentives. Regressions of the number of mayoral candidates (where district magnitude is held constant) on municipal population (included in the dataset), however, indicated no substantive support for this hypothesis - it holds true only for MMPs.

12. For a more detailed discussion see Benoit (N.d.).

\section{References}

Amorim-Neto, O. \& Cox, G.W. (1997). Electoral institutions, cleavage structures, and the number of parties, American Journal of Political Science 41(1): 149-174.

Benoit, K.R. (N.d.). The endogeneity problem in electoral studies: A critical reexamination of Duverger's mechanical effect, Electoral Studies.

Benoit, K.R. (2000). Which electoral formula is the most proportional? A new look with new evidence, Political Analysis 8(4): 381-388.

Blais, A. \& Carty, R.K. (1987). The impact of electoral formulae on the creation of majority governments, Electoral Studies 6: 209-218.

Blais, A. \& Carty, R.K. (1991). The psychological impact of electoral laws: Measuring Duverger's Elusive Factor, British Journal of Political Science 21: 79-93.

Carey, J.M. \& Shugart, M.S. (1995). Incentives to cultivate a personal vote: A rank ordering of electoral formulas, Electoral Studies 14(4): 417-439.

Cox, G. (1997). Making votes count: Strategic coordination in the world's electoral systems. Cambridge, UK: Cambridge University Press.

Cox, G.W. \& Shugart, M.S. (1991). Comment on Gallagher's 'proportionality, disproportionality and electoral systems', Electoral Studies 10.

Duverger, M. (1951). Political parties: Their organization and activity in the modern state. New York: Wiley.

Engstrom, R.L. \& McDonald, M.D. (1993). 'Enhancing factors' in at-large plurality and majority systems: A reconsideration, Electoral Studies 12(4): 385-401.

Gallagher, M. (1991). Proportionality, disproportionality, and electoral systems, Electoral Studies 10(1): 33-51.

Lipjhart, A. (1994). A study of twenty-seven democracies 1945-1990. New York: Oxford University Press.

Loosemore, J. \& Hanby. V. (1971). The theoretical limits of maximum distortion: Some analytic expressions for electoral systems, British Journal of Political Science 1: 467-477. 
Ordeshook, P.C. \& Shvetsova, O.V. (1994). Ethnic heterogeneity, district magnitude, and the number of parties, American Journal of Political Science 38(1): 100-123.

Palfrey, T. (1989). A mathematical proof of Duverger's law, in P. Ordeshook (ed.), Models of strategic choice in politics. Ann Arbor: Michigan.

Rae, D.W. (1967). The political consequences of electoral laws. New Haven, CT: Yale University Press.

Rae, D.W., Hanby, V. \& Loosemore, J. (1971). Thresholds of representation and thresholds of exclusion: An analytic note on electoral systems, Comparative Political Studies 3: 479_ 488.

Reed, S.R. (1990). Structure and behaviour: Extending Duverger's law to the Japanese case, British Journal of Political Science 20: 335-356.

Riker, W.H. (1976). The number of political parties: A reexamination of Duverger's law, Comparative Politics 9: 93-106.

Sartori, G. (1986). The influence of electoral systems: Faulty laws or faulty method? in B. Grofman \& A. Lijphart (eds.), Electoral laws and their political consequences. New York: Agathon Press.

Taagepera, R. \& Laakso, M. (1980). Proportionality profiles of west European electoral systems, European Journal of Political Research 8(4): 423-446.

Taagepera, R. \& Shugart, M.S. (1989). Seats and votes: The effects and determinants of electoral systems, New Haven, CT: Yale University Press.

Taagepera, R. \& Shugart, M.S. (1993). Predicting the number of parties: A quantitative model of Duverger's mechanical effect, American Political Science Review 87(2): 455-464.

White, H. (1980). A heteroscedasticity-consistent covariance matrix estimator and a direct test for heteroscedasticity, Econometrica 48: 817-838.

Wildgen, J.K. (1972). Electoral formulae and the number of parties, Journal of Politics 34: 943-950.

Address for correspondence: Kenneth Benoit, Department of Political Science, Trinity College, University of Dublin, Dublin 2, Ireland

Phone: +353 1 608-2491; E-mail: kbenoit@tcd.ie 